www.jmscr.igmpublication.org

Impact Factor 5.84

Index Copernicus Value: 83.27

ISSN (e)-2347-176x ISSN (p) 2455-0450

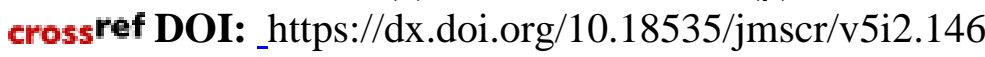

Journal Of Medical Science And Clinical Research

Original Article

\title{
A study of Clinico-Haematological Profile of Acute Dengue Fever
}

\author{
Authors \\ Neha Shah ${ }^{1}$, Naimish Patel $^{2}$ \\ ${ }^{1}$ Associate Professor, ${ }^{2}$ Assistant Professor, \\ GCS Medical College Hospital \& Research Centre, \\ Ahmedabad, Gujarat, India \\ Corresponding Author \\ Naimish Patel \\ Email: naimishap13@gmail.com.Phone No:09879636022
}

\begin{abstract}
Dengue fever is caused by Flavivirus is a common ailment occurring in the community. The transmission by means of mosquito bites makes it all the more threatening to society. Aim of the study was to establish clinical and haematological correlation of dengue viral infection. A study of 107 indoor sero-positive dengue fever cases was done prospectively. Clinical features and haematological reports were noted and analyzed statistically. Hospitalisation duration data were noted and analysed. Total 503 clinically suspected patients were tested at tertiary care level hospital; out of which 107(21.2\%) patients were positive for acute dengue fever. Female: Male ratio, and adult:old ratio was 1.14;1 and 4.5:1, respectively. The maximum $71 \%$ cases of acute dengue fever were recorded between the months of September 2016 to December 2016. Clinically fever is commonest symptoms presentation in $97.2 \%$ patients, followed by muscle pain and vomiting in $87.3 \%$, respectively. Least common clinical presentation was skin rashes and haemorrhagic manifestations in $1.5 \%$ cases each. Anemia, leucopenia, and thrombocytopenia were noted in 85(79.5\%), 50(46.2\%) and 78(72.8\%) of patients, respectively. The associated diseases were noted 42(39.2\%) deaths. The hospitalisation days were 6.3 days/patient. High grade fever, muscle pain, vomiting anemia leucopenia with lymphocytosis, thrombocytopenia were detected commonly, while skin rashes, shock and haemorrhagic diathesis were rare complication of primary dengue fever cases looked, The associated clinical condition i.e., malaria, enteric fever etc. should be looked, they might be responsible for complications in primary dengue fever cases.

Keywords: Clinico-haematological, Dengue, Fever.
\end{abstract}

\section{Introduction}

Dengue fever (DF) is a febrile illness caused by a RNA flavivirus. Viruses are transmitted by female Aedes egypti or rarely by Aedes albopictus mosquito. The mosquito breeds in stored clean water near human residence and insides room i.e. flower pot, water coolers, air conditioners etc. and it bites during day times. Aedes egypti primarily lives in the tropical and sub tropical region. ${ }^{(1)}$ The viruses are found in salivary gland of mosquitoes which allows it to survive from season to season. There are 4 serotypes namely DENV1, DENV2, DENV3, and DENV. In Southeast Asia, dengue fever is due to two DENV2 viruses. Each virus serotype provides specific lifetime immunity by homotypic, neutralising antibody and short term 
cross immunity by heterotypic non neutralising antibody. ${ }^{(2)}$ The acquired immune response to dengue infection varies and depends on primary or secondary infection. Primary immune response was seen in individuals who were not immune to dengue infection and secondary immune response is observed in patients who have had a previous dengue infection. Dengue fever begins after average 4-7 days of incubation ${ }^{(1)}$. The symptoms of classic dengue fever are fever, muscle pain, retro bulbar pain, severe joint pain, swollen lymphnodes and rashes. Dengue Haemorragic Fever (DHF) is more severe form of viral fever and common in children. DHF is commonly due to secondary infection of DENV2 virus preceded by DENV1 virus. Secondary DF may occur at 5 to 20 years interval after primary infection. Preexisting antibody from DENV1 virus infection fails to neutralise DENV2 virus and may enhance viral uptake and replication in mononuclear phagocytes ${ }^{(3)}$. These phenomena may result in activation of mediators and complements and clotting cascade leading to DHF. Its symptoms are severe headache, fever, rashes and evidences of haemorrhage in the body e.g. petechiae (small red or purple spots or blisters under the skin) bleeding nose or gums, black stools, easy bruising. On application of tourniquet on limb may results in petechiae on distal part of the limb skin. Dengue Shock Syndrome (DSS) may be due to sudden increase in permeability of capillary. It is associated with oedema and serositis e.g. pleural effusion and or ascites. DSS may last for 48 hours and a grave complication if not treated in time ${ }^{(4)}$. Dengue fever is diagnosed by $\operatorname{IgM}$ antibody detection by ELISA or paired serology or detection of antigen by ELISA or RT- PCR during acute phase. IgG antibody positive suggests past infection. Management of dengue fever is symptomatic with antipyretic i.e. paracetamol without non steroidal antiinflammatory drugs (NSAID), fluid therapy, platelet replacement not needed. DHF should be treated with blood transfusion and DSS by optimising fluid therapy rapidly ${ }^{(6)}$.

\section{Material \& Methods}

Total 503 patients blood samples were collected from clinically suspected dengue fever patients

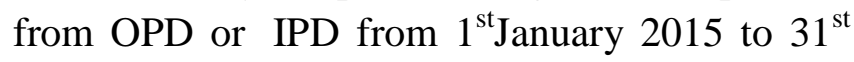
December 2015 at tertiary care hospital and all blood samples were tested for dengue fever profile. Blood sample was collected with standard laboratory precautions. All samples were tested for Qualitative capture ELISA IgM antibody, Qualitative capture ELISA IgG antibody and NS1 antigen detection by Rapid serological test (Card method). The patients having IgM antibody and/or NS1 antigen in blood were isolated and listed as dengue fever cases. ${ }^{(6)}$ All the indoor cases records of DF patients were analyzed in structured performa. The performa included the information of patient's registration data, clinical features, investigation profile i.e. laboratory investigations and imagine study in detail and were analyzed by standard statistical method. The duration of hospitalisation and associated diseases were also recoded and analyzed with other data. Indoor patients with NS1 antigen and/or IgM antibody positive were included in study as acute dengue viral fever. The patients with only IgG antibody in blood excluded as it suggests old dengue viral infection.

\section{Exclusion \& Inclusion:}

All indoor patients with dengue test profile with NS1 Antigen and/or IgM antibody positive were included in study as acute dengue viral infection. Patients with only IgG antibody in blood were excluded as it suggests old dengue viral infection.

\section{Results}

The clinically suspected 503 cases of suspected cases of dengue fever were tested for dengue fever profile, The total cases 107 (23.1\%) were positive, i.e, either NS1 antigen and /or anti IgM antibody positive for dengue fever. (7) Age distribution shows the patients below 40 years and above were $87(81.3 \%)$, and 20(18.2\%), respectively. 
Table1: Comparison of study at Tertiary care Hospitals.

\begin{tabular}{|c|c|c|c|}
\hline Variables & Present study & Study at & Study at \\
\hline & GCS Hospital & L.G. Hospital ${ }^{(7)}$ & Pune $^{(8)}$ \\
\hline Study Duration & Jan 15 to Dec 15 & Oct 13 to Jan 13 & $\begin{array}{c}\text { Nov. } 12 \text { to April } \\
12 \\
\end{array}$ \\
\hline No. Of samples & \multirow[b]{2}{*}{$503 / 107(21.2 \%)$} & \multirow[b]{2}{*}{$169 / 44(26 \%)$} & \multirow[b]{2}{*}{$452 / 98(21.6 \%)$} \\
\hline Tested/Positive for dengue fever cases (\%) & & & \\
\hline \multicolumn{4}{|l|}{ Most common symptoms cases $(\%)$} \\
\hline Fever & $104(97.1 \%)$ & $56(88.60 \%)$ & $67(95 \%)$ \\
\hline Muscle pain & $93(86.9 \%)$ & $53(75 \%)$ & $62(87.3 \%)$ \\
\hline Vomiting & $84(78.5 \%)$ & $69 \%$ & $54(76 \%)$ \\
\hline \multicolumn{4}{|l|}{ Platelet count } \\
\hline$<50000 / \mathrm{L}$ & $33(30.8 \%)$ & $26(36.30 \%)$ & $41(57 \%)$ \\
\hline $50000-150000 / \mu \mathrm{L}$ & $45(42 \%)$ & $32(44.90 \%)$ & $17(24.10 \%)$ \\
\hline$>150000 / \mu \mathrm{L}$ & $21(18.6 \%)$ & $13(18.80 \%)$ & $13(18.90 \%)$ \\
\hline
\end{tabular}

As shown in Table 1, the acute dengue fever cases presented with high grade fever with severe body ache and thrombocytopenia.

\begin{tabular}{|l|l|l|}
\hline \multicolumn{3}{|c|}{ Table 2: Laboratory data of Dengue fever cases } \\
\hline Haemoglobin \& Anemia & HB Level & Cases $(\%)$ \\
\hline Normal & $>12 \mathrm{mg} / \mathrm{DL}$ & $21(19.6 \%)$ \\
\hline Mild & $9-12 \mathrm{mgDL}$ & $55(51.8 \%)$ \\
\hline Moderate & $7-9 \mathrm{mg} / \mathrm{DL}$ & $15(14 \%)$ \\
\hline Severe & $<7 \mathrm{mgDL}$ & $15(14 \%)$ \\
\hline Leucocytes & Total $(/ \mathrm{cmm})$ & Cases \\
\hline Leucopenia & $<4000 / \mathrm{cmm}$ & $50(46.5 \%)$ \\
\hline Normal leucocytes & $4000-11000 \mathrm{cmm}$ & $47(43.4 \%)$ \\
\hline Leukocytosis & $>11000 \mathrm{cmm}$ & $11((10.3 \%)$ \\
\hline
\end{tabular}

Table 2 shows, anemia \& leucopenia were noted in 85 cases (78.8\%) and 50 cases(46.7\%), respectively.

\begin{tabular}{|l|l|}
\hline Table 3: Hospitalisation duration- cases (\%) \\
\hline Days $1-3$ & $36(33.6 \%)$ \\
\hline Days 3-7 & $54(50.5 \%)$ \\
\hline Days $>7$ with associted disease & $15(14.2 \%)$ \\
\hline Days $>7$ without associated disease & $2(1.8 \%)$ \\
\hline
\end{tabular}

Table 3 shows 90 cases $(84.1 \%$ ) were indoor for a range 1-7 days; suggesting a brief period of hospitalisation for symptomatic treatment, while more than 7 days hospitalisation was noted in 15 cases(14.2\%) with associated disease, and 2 cases(1.8\%) without associated disease.

\begin{tabular}{|l|l|}
$\mid$ Table 4: Immunological Data of dengue cases: \\
\hline NS1 antigen Positive & $56(52 \%)$ \\
\hline NS1 antigen and /or IgM antibody positive & $107(100 \%)$ \\
\hline IgM antibody positive & $50(47.9 \%)$ \\
\hline IgG antibody positive & $32(30.9 \%)$ \\
\hline IgM antibody +IgG antibody positive & $30(28.2 \%)$ \\
\hline
\end{tabular}

Table 4: shows Immunological data (Multiple responses) of 107 positive cases of dengue fever. 


\section{Discussion}

DF is more common in in children and adult than old age persons. The mosquito bites during day time. The children and adult are more mobile than old age persons and hence more likely to be bitten. Female:male sex ratio is $1.14: 1$, it suggests nearly equal sex distribution. 70\% \% cases of DF were recorded between September to December 2015 (monsoon season) as compared to $30 \%$ cases of DF which were recorded between January to August 2015; during winter and summer season. It suggests dengue is more in monsoon season as more water pits are formed in monsoon season for breeding of mosquitoes. As shown in table 1, clinically fever was presenting symptom 97\% cases followed by muscle pain in $86.9 \%$ cases, vomiting in $78.5 \%$ and skin rash in $1.4 \%$ cases. The skin rashes are rare feature in primary DF but are common in secondary DF or DHF. ${ }^{(9)}$ Laboratory profile suggests leucopenia and thrombocytopenia is due to direct suppression of bone marrow by DF virus. Anemia is due to poor nutritional status of affected community. Our results are comparable with studies as shown in table 1. Elevated SGPT were noted in 5 cases (4.6\%). Pleural effusion and ascites were detected by ultrasonography only in 6 cases $(5.6 \%)^{(10)}$ The study community was exposed to primary infection, is its clinical complications such as DHF and DSS were not detected. The secondary DF is usually associated with with fatal end stage diseases, chronic liver failure with portal hypertension, while $1(0.9 \%)$ case was associated with falciparum malaria with multiple organ dysfunctions syndrome. The associated diseases were diagnosed in 42 cases $(39.2 \%)$ i.e. respireatory disease in 9 cases $(8.4 \%)$; enteric fever, acute viral hepatitis \& falciparum malaria in 6 cases in each (5.6\%); chronic liver disease in 4 cases $(3.7 \%)$; tuberculous Lymphadenopathy , acute gouty arthritis and urinary tract infection in 1 case $(0.93 \%)$. All were mere coincidental clinical disease. The associated enteric fever and malaria suggest associated seasonal infection in studied community.

\section{Conclusion}

High grade fever, muscle pain, and vomiting are main clinical symptoms while skin rashes and haemorrhagic manifestations are rare manifestations of primary DF. Leucopoenia and thrombocytopenia detected as common laboratory finding. Abnormal LFT, pleural effusion and ascites are rare manifestations of primary DF. DHF and DSS are not a complication of primary DF. Symptomatic therapy and management of associated disease is more important as mortality depends more on associated disease. Common associated infective diseases include enteric fever, malaria and respiratory diseases.

\section{Acknowledgements}

Authors would like to acknowledge the outstanding support made by Dr. Rathod Natubhai RMO and Mr. Vipul, in-charge, Medical Record Department, GCSMC,H\&RC and we are thankful for their valuable contribution.

\section{References}

1. Gordon C., Alimmuddin I., Dengue and Dengue haemorrhagic fever In Manson's Tropical Disease. $22^{\text {nd }}$ ed. Elsevier Saunders, 2009; 753.

2. Rico-Hesse R., Molecular evolution and distribution of dengue virus type 1 and type 2 in nature. Virology $1990174^{(2)}$ : 479-493

3. Gordon C., Alimmuddin I., Elsevier chapter 41, Dengue and Dengue haemorrhagic fever. Manson's Tropical Disease, $22^{\text {nd }}$ edition, Saunders 2009, page 756. K.Park, Bhanot, chapter 5, Epidemeology of communicable diseases. In: Park's Textbook of Preventive and social medicine, $22^{\text {nd }}$ ed. Banarsidas Bhanot 2013; 225-226.

4. Nimmannitya $S$, Thhisyakon U, Hemsechart V. Dengue Haemorrhagic fever with unusual manifestation. Southeast Asian J Trop Med Public Health 1987; 18: 398406. 
5. Ashka Kodnani, D.S.Joshi, et.al. ClinicoHaematological study of dengue cases, GCSMC J Med. Sci. January-June 2014 (III) No (I); 53.

6. Chanama, S. et al Analysis of specific IgM responses in secondary dengue virus infections: levels and positive rates in comparison with primary infections. J. Clin. Virol. 31, 2004, 31; 185-189.

7. K.Park, Bhanot, Epidemeology of communicable diseases, In; Park's Textbook of Preventive and social medicine, $22^{\text {nd }}$ ed. Banarsidas Bhanot 2013; 229-232.

8. Cesilia D, Kakade MB, Bhagat AB. Dengue case study. Viro J. 2011, 46:27-32

9. WHO (2009), Dengue, Guidelines for Diagnosis, treatment, prevention and control New edition, 2009 page 12-15. Available from: www.who.int/tdr/publication/documents/d engue-diagnosis

10. K.Park, Bhanot, Epidemeology of communicable diseases, In; Park's Textbook of Preventive and social medicine, $22^{\text {nd }}$ ed. Banarsidas Bhanot 2013; 232-233. 